\title{
Innovation Activities of Enterprises of the Coal Industry to Improve Productivity
}

\author{
Larisa Kalacheva ${ }^{1}$, Diana Savon ${ }^{2},{ }^{1}$ Open JSC TSNIEIugol, ${ }^{2}$ NUST "MISIS"
}

\begin{abstract}
The paper presents a detailed analysis of the evaluation of the situation with labor productivity in the coalmining organizations and identification of reserves (establishing untapped opportunities to save resources), resulting from the impact, interconnection and interdependence of individual factors. It is concluded that although there has been growth in all of its federal districts and coal basins in recent years, but productivity is lower than that of the leading foreign corporations from countries - Russia's partners in the BRIC countries. The methodical approach is to identify internal reserves of labor in the coal industry on the basis of decrease (increase) in the estimated number of workers due to changes in the quantitative and qualitative factors. According to the authors, a successful transition to a market economy is more important than a scientific solution to the problem of finding reserve efficiency by productivity specialists. It is possible to solve it only on the basis of the ordering system to encourage a rational activity of a specialist, including virtually all aspects of labor processes taking into account the aggregate technological, technical, economic, organizational and legal factors.
\end{abstract}

Keywords - Coal production, growth reserves, labor productivity.

\section{INTRODUCTION}

It is not a secret that the Russian economy suffers from low productivity. According to the Organization for Economic Cooperation and Development (OECD), the productivity of labor in Russia is $24 \$$ per person per hour, i.e., $39 \%$ of the US level - this is the last place among all the participating countries. The worst situation is only in Mexico. The companies from the list of leaders of the domestic business "Expert-400" per employee have an average of 183 thousand \$ in annual revenue. This is 3.4 times lower than in the largest companies in Japan, almost three times less than in Western Europe and the US and 1.7 times less than that of the leading corporations of the countries - Russia's partners in BRIC. In recent years, the coal industry has almost completely curtailed the work on the synthesis and dissemination of progressive inter-sectoral and international experience in the management of the evaluation system and the formation of changes in labor productivity experts (Popov, Gribin \& Mohnachuk, 2013).

\section{PROSPECTS FOR THE DEVELOPMENT OF THE COAL INDUSTRY}

Speaking about the prospects of development of the coal industry, it should be noted that in Russia, the demand for coal is presented in all subjects of the Federation, and the coal is mined today in 24 subjects. Dynamics of coal production by federal districts of the study period is presented in Fig. 1.

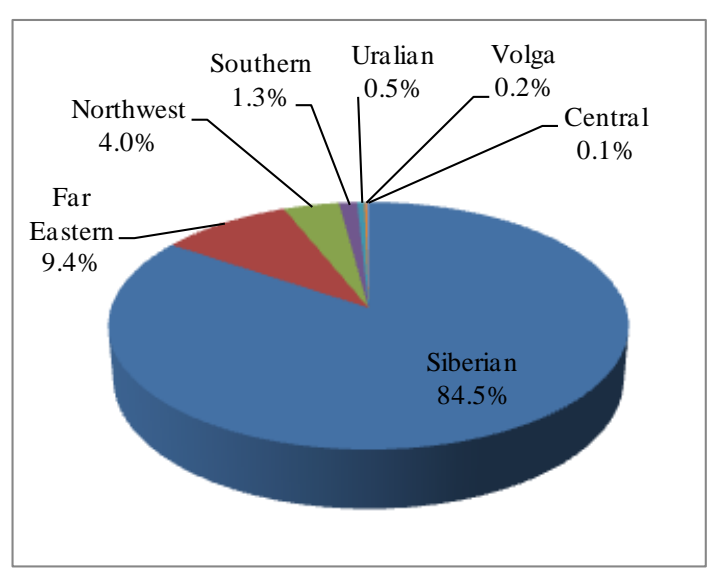

Fig. 1. The distribution of coal production by federal districts in 2013 .

Coal production in Russia in 2013 decreased compared to 2012 by $0.8 \%$ to 352,109 million tons. Opencast mining in 2013 increased by $0.9 \%$ to 251,1 million tons, underground way - declined by $4.7 \%$ to 100.974 million tons. Analyzing the structure of production by federal districts based on data of CDU TEK, the largest share in total coal production belongs to the Siberian Federal District $-84.5 \%$, the Far Eastern Federal District $-9.4 \%$, Northwest $-4 \%$, Kuznetsk basin $57.6 \%$. The main consumers of coal in the domestic market: firstly, a large electric power (33\%), and second, the electrical and thermal power stations (22\%), and - third, metallurgy $(16 \%)$.

In the Kuzbass average labor productivity in the industry for ten years has doubled and reached 200 tons per person per month, although it continues to lag behind the global average. To modernize the facilities for the extraction and processing of coal, 382 billion rubles of investments have been drawn since 2002, thereby creating 55 new high-performance enterprises for extraction and processing of black gold, whose equipment meets international standards of technical equipment and security.

Only in 2012 for the modernization of the coal enterprises of the region 58 billion rubles were invested, and only in the fixed assets of companies -83 billion rubles. Currently, the Kemerovo region produces $65 \%$ of Russia's total coal and $75 \%$ of the volume of coking coal. The volume of coal production in Kuzbass reached the level of production by leading coal-producing countries, such as Germany (by this indicator Kuzbass was ranked seventh in the world in the ranking of countries). In January-August 2014, in Kuzbass mines 137.3 million tons were extracted, i.e., an increase of $3.1 \%$ compared to the same period of 2013 . 
In the Southern Federal District, across Rostov region, in 2012 the coal enterprises extracted 5 million 280 thousand tons of coal that made $111.9 \%$ of the volume of 2011. In 2012 the volume of investment into the coal companies accounted for more than 2 billion rubles. The number of the operating clearing faces increased, labor productivity and average daily load of a clearing face grew. The staff of Sadkinskoye mine office for the first time in East Donbass extracted more than 2 million tons of anthracite on mine with one clearing face (Popov, Gribin \& Mohnachuk, 2013).

Following the results of 2012, at the coal-mining enterprises of the region for the first time during the post-crisis period the average monthly salary in the coal companies of area increased by $27 \%$ - to 18.6 thousand rubles. It corresponds to a regional average level; however, it is not enough, considering working conditions of miners. Low compensation is the main reason for that deficiency of qualified specialists who leave the companies of the coal industry now.

In 2014 during 9 months, coal mining in Russia was reduced in comparison with the similar period of 2013 by $0.7 \%$ to 254.523 million tons; thus, export grew by $10.2 \%$ to 115.2 million tons (materials of the central dispatching management of energy industry (TsDU energy industry). Coal mining in the open way in 9 months decreased by $1.5 \%$ to 178.8 million tons, and in the underground way - grew by $1 \%$ to 75.7 million tons. Production of the largest coal companies for the reporting period made: JSC SUEK - 68.4 million tons of coal $(-0.7 \%$ to an indicator of the corresponding period of 2013), JSC Kuzbassrazrezugol Coal Company (enters UMMC) - 32.58 million tons ( $-2.7 \%)$, JSC HK SDS-Ugol 21.4 million tons $(+12.6 \%)$, JSC Vostsibugol Company 7.85 million tons $(-32.6 \%)$, JSC UK Yuzhny Kuzbass (enters "Mechel") - 9.35 million tons $(-15.2 \%)$, JSC OUK Yuzhkuzbassugol (enters Evraz) - 8.9 million tons (+0.6\%), JSC HK Yakutugol (enters "Mechel") - 6.95 million tons (-6.7\%), JSC Raspadskaya (82\% belong to Evraz) 6.876 million tons (Popov, Gribin \& Mohnachuk, 2013).

\section{FACTORS AFFECTING THE LEVEL OF LABOR PRODUCTIVITY}

Processes of management of labor productivity are influenced by a large number of the factors promoting its increase and decrease. In mountain and economic literature it is accepted to understand the reasons causing change of level and dynamics of this complex indicator as factors. The conditions, processes and the phenomena strengthening (reducing) influence of this or that factor have also a certain impact on it. It is necessary to mention the most important of them:

- climatic and mining-and-geological conditions, characteristic of mining branches;

- material factors of change of labor productivity (modernization of the equipment, replacement of the outdated equipment, increase in the level of mechanization and automation of processes of production, introduction of new technologies, use of new materials and power sources, development of the designs reducing labor input of work, improvement of quality of production);

- organizational factors (improvement of the organization of management, production, work);

- social factors (material and moral interest of the personnel in results of activity, the relation to work and labor discipline, health protection and welfare, economic and legal security, stability, relationship of staff and workplace climate, fidelity of the organization, feeling of participation in common cause).

When studying the economic nature of labor productivity in economic literature much attention is paid: to disclosure of modern approaches to this concept; to labor productivity growth; to labor productivity indicators depending on a way of measurement of results of activity, from a type of the considered expenses, from the purpose and the level of its change; to methods of measurement of labor productivity by means of private indicators, multi-factor methods, a method of definition of change of cumulative labor productivity, multicriteria methods; factors and conditions of measurement of labor productivity (material, organizational, social and economic).

Opening the considered expenses of resources, and also ways of their measurement in the conditions of market economy taking into account foreign, interindustry and branch experience indicators in value terms can be allocated (at the prices and rates of the basic period): results of economic activity (proceeds from sales of the made production, the income, profit); the expenses connected with attraction and use of a resource (a salary, social payments, costs of training, labor protection, etc.); expenses of fixed capital (depreciation, the equipment working hours for production); costs of materials and energy; expenses of information resources.

Completeness of the account and combination of the specified expenses can be implemented in practice depending on the purposes and research problems in various options.

For efficient management of the labor productivity in the market conditions it is important to count production found time and to do not allow growing of joint costs of production. Thus, increase of unit labor requirements for effective and economic production has to be followed, as a rule, by more rapid growth of volumes of its realization, significant improvement of quality, economy of resources, receiving additional profit.

The analysis of the main economic indicators of the enterprises of coal branch influencing labor productivity showed that the profit considerably decreased to the taxation in 2013 in comparison with 2012. Shipped goods of own production in the actual prices (without the VAT) on primary activity decreased by 6269543 thousand rubles or by $1.5 \%$ in 2013 in comparison with 2012. The salary fund increased both in 2012 in comparison with 2011, and in 2013 by $9.6 \%$ and $4 \%$, respectively. Payments of social character in 2012 increased by 258917.7 thousand rubles or by $12.4 \%$ and in 2013 - by 273224.2 thousand rubles or by $11.6 \%$. The average monthly salary of one worker of administrative-andmanagement personnel increased by $7.9 \%$ in 2013 in 
comparison with 2012. Full prime cost of 1 ton of coal mining reached 1440.52 rubles in 2013.

In process of management of labor productivity in the organization the system of the generalizing, private and auxiliary indicators can be used. In practice average annual, daily average and hourly average development of production by one worker, and also average annual value of production on one working in value terms belong to the generalizing indicators. Auxiliary indicators characterize expenses of time for performance of unit of this or that type of works or the volume of the made production in unit of time.

The most important indicator thus is average annual value of production by one worker. Its size as practice shows depends not only on development of workers, but also on their specific weight in the total number of the industrial and production personnel, and also on number of the days worked and duration of the working day.

The analysis of practice of management of labor productivity testifies that, despite liquidation of mines with adverse mining-and-geological conditions in the course of restructuring of branch, work of miners remains difficult and dangerous, so the number of mines over the 3rd category of danger increased by 2,7 percentage points. More than $79 \%$ of mines are dangerous on dust. The quantity of the shah and dangerous on mountain increased by 15,8 points. Average depth of conducting mining operations was increased by 33 meters.

Such conditions of production have a negative impact on productivity and efficiency of work, change of the main technical and economic indicators of work characterizing the directions of development of the coal-mining organizations cause additional nervous tension on an organism of workers, lead to work intensification, demand special attention and responsibility for productivity of work and safety of the personnel.

The major indicator influencing labor productivity level is the number of the personnel. Research on the dynamics of the personnel shows that from year to year it continues to decrease.

Very significant factor testifying the efficiency of the organization of production and work and stimulating salary role in the coal-mining enterprises is the use of fund of working hours. It is possible to estimate influence of completeness of use of manpower by number of the fulfilled days and hours of one worker for the analyzed time period, and also by the extent of use of fund of working hours. The analysis showed that in the last decade the number of the fulfilled days by one worker in a month has increased. The indicator of the average duration of working year is one of social and economic characteristics of work. Reduction of losses of working hours is one of reserves of increase in production and growth of labor productivity.

The major indicator influencing labor productivity level is the number of the personnel. The average number of workers at the coal mining and processing enterprises for the period of 2006-2014 showed a decrease tendency (see Fig. 2). Especially, the average number of labor potential decreased in
2013 by 28.3 thousand people, or by $14.8 \%$ in comparison with 2007 and made 163.1 thousand people. For the last three years $(2011-2013)$ also a decrease in the number of workers at the coal production and processing enterprises has been observed, i.e., a decrease by 5.5 thousand people, or by $3.3 \%$; decrease in the number of workers performing a primary activity accounted for 158.4 thousand people, decrease in the number of workers in coal mining - 107.9 thousand people, by ITR - 21.0 thousand people, workers of administrative-andmanagement personnel -8.4 thousand people (Popov, Gribin \& Mohnachuk, 2013).

Analyzing the average number of workers performing a primary activity at the coal mining and processing enterprises for federal districts, the tendency to decrease has also been noticed. In the country, decrease accounted for 1495 people or $0.9 \%$ for $2011-2013$, and also in all districts except for Volga district, where the number of workers increased by 2.1 times. It is connected with activity of JSC Orenburgugol where coal mining increased by $18.8 \%$ in comparison with 2012. In the Pechora area, the number of workers performing a primary activity decreased by 1635 people, or by $14.8 \%$, on the Donets basin - by 1409 people, or by $18.3 \%$, and on the Kuznetsk pool increased by 3202 people, or by $3.2 \%$ where coal mining increased by $0.7 \%$ in comparison with 2012 (Popov, Gribin \& Mohnachuk, 2013).

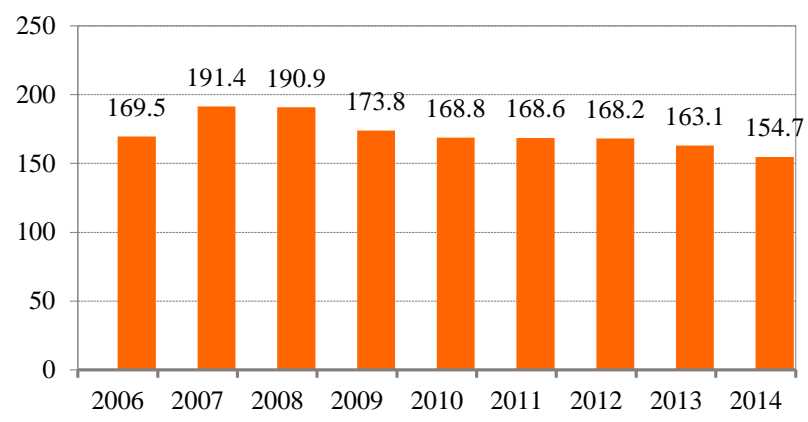

Fig. 2. Dynamics of workers at the coal mining and processing enterprises of the Russian Federation, one thousand persons.

Among the most significant indicators that show the level of production and work, as well as the stimulating role of wages, is the average load acting on the working face in mines. Average daily coal mining from one face increased from $1052 \mathrm{t}$ in 2000 to $2403 \mathrm{t}$ in 2009, i.e., by 2.3 times, and in a complex mechanized faces - from 1297 to $3303 \mathrm{t}$ (by 2.55 times).

In 2013 in comparison with 2011 average daily coal mining increased by 42.5 million tons per day, or by $4.5 \%$. In 2014 for the first half of the year the indicator reached 944.3 million tons per day. Average daily coal mining from 1 operating clearing face accounted for 3851 tons, in 2013 - 3780 tons which increased in comparison with 2011 (2866 t) by 914 tons or by $31.9 \%$, and from the one complex mechanized face growth was $1.9 \%$ or in 2013 (4392 t) in comparison with $2011(3685 \mathrm{t})-707$ tons. In the first half year of 2014 average daily coal mining of 1 operating clearing face made 3851 tons, and of the complex mechanized face -4322 tons. 


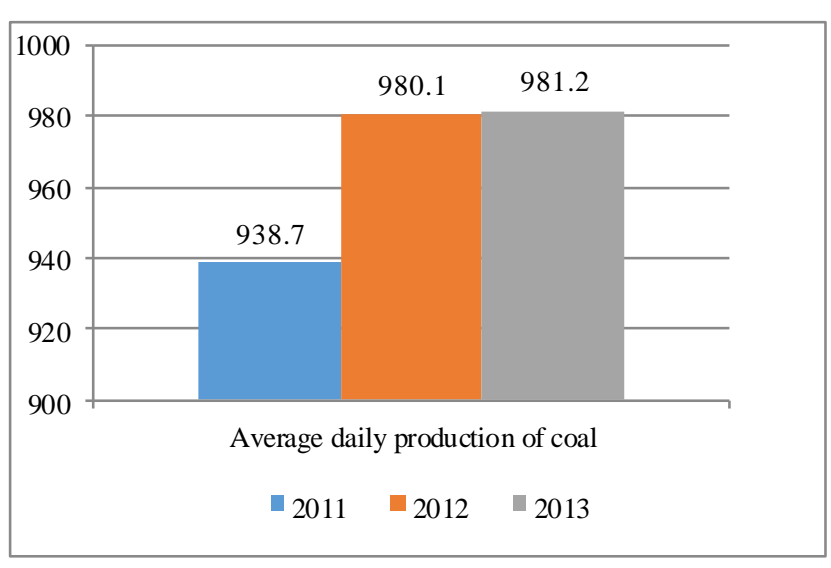

Fig. 3. Dynamics of average daily coal mining for 2011-2013.

Significant improvement of work of clearing faces on mines testifies to increase of efficiency of use of the mining-transport equipment in power and in time, accurate interrelation of work of mining and transport equipment, the organization of work of adjacent processes.

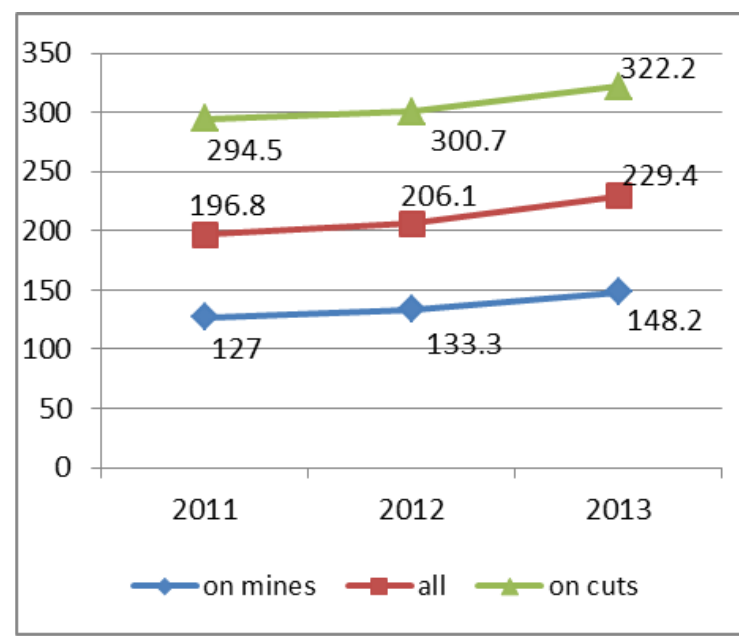

Fig. 4. Dynamics of average monthly labor productivity of the worker in coal mining for 2011-2013.

Analyzing dynamics of average monthly labor productivity of the worker in coal mining for the last three years, we observe growth by 1.2 times. On the Pechora pool, the gain of labor productivity of workers of primary activity in 2012 made $11.3 \%$ in comparison with 2011; in 2013 a decrease in a gain by $1.8 \%$ was observed; on the Donets basin in 2012 in comparison with 2011 rate of a gain was $2.9 \%$, in 2013 a gain $-6.6 \%$ that is by $3.7 \%$ more than in 2012 . Rates of a gain on the Kuznetsk pool remained almost invariable (Popov, Gribin \& Mohnachuk, 2013).

Shipment of an industrial output on one worker presented in Fig. 5, in 2012 made 2767.9 thousand rubles $(-15.7 \%$ to the level of 2011), in 2013 the increase made 210.9 thousand rubles or $7.6 \%$ in comparison with 2012. In 2014 for the first half of the year shipment of an industrial output on one worker reached 2037.3 thousand rubles.
Essential growth of labor productivity at an underground way of coal mining is caused by closing of unprofitable, low effective mines in the course of restructuring of branch.

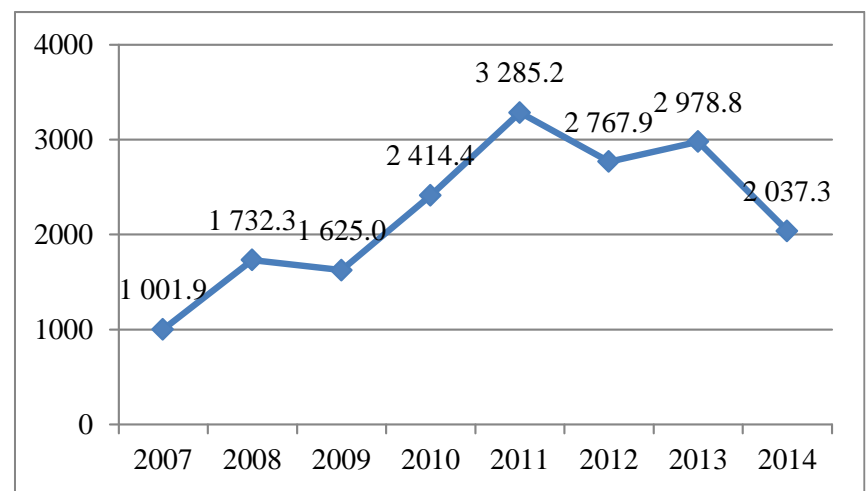

Fig. 5. Dynamics of shipment of an industrial output on one worker at the coal-mining and coal processing enterprises, thousand rubles.

The analysis of practice of management of labor productivity testifies that, despite liquidation of mines with adverse mining and geological conditions in the course of restructuring of branch, work of miners remains difficult and dangerous. More than $79 \%$ of mines are dangerous on dust (the quantity increased by 15,8 points). Average depth of conducting mining operations was increased by 33 meters (Popov, Gribin \& Mohnachuk, 2013).

In practice of the coal-mining organizations, reserves of growth of labor productivity represent unused opportunities of reduction of expenses of work under the influence of certain quantitative and qualitative factors. In this regard, each type of an intra-production reserve can be considered in relation to the concrete factor operating in these or those conditions. Such an approach allows systematizing and structuring reserves of growth of labor productivity in the coal-mining organization, carrying out their system and complex analysis in management process, establishing the reasons of losses of resources and developing concrete recommendations and organizational and technical actions for their elimination (Popov, Gribin \& Mohnachuk, 2013).

\section{CONCLUSION}

In the coal-mining organization, reserves can be systematized in relation to four levels of management of productivity - at a workplace; on a site, in shop; at the level of the organization; in the company, joint-stock company. It should be noted that in coal branch it is accepted to refer to category of reserves, first of all, production losses of working hours and unproductive (inefficient) expenses of work. Unplanned idle times belong to such reserves, unforeseen absence from work, in particular, truancies, the work expenses connected with irrational use of the equipment (machines and mechanisms), the bad organization of production and work. Systematic identification and realization of intra-production reserves are reached on condition of rational distribution of obligations of the personnel for standardization of productions (Popov, Gribin \& Mohnachuk, 2013). 
In modern conditions questions about the growth of volumes of coal-mining production, and increase of its efficiency, profitability, every possible economy of resources get, decrease in prime cost and improvement of quality and competitiveness of production, taking measures to reduction of labor input of works, essential growth of quality of work became very important and very difficult. In this regard, within the research of intra-production reserves of growth of labor productivity the special importance is gained by quality of analytical work in the coal-mining organizations. Not less important direction in identification of intra-production reserves is economic and mathematical modeling. Results of the teams working in the high-performance mode (i.e. high efficiency with the minimization of traumatism) indicate the available reserves to improve production efficiency and ensure its safety in the organization of production processes. Experience of functioning of such coal enterprises as JSC "Raspadskaya", JSC “OUK Yuzhkuzbassugol”, JSC "UK Kuzbassugol" using high-performance systems such as "Joy", "Langvol", "ABM" etc. shows that application of new basic technologies and modern equipment allows to reduce a difference in labor productivity between the domestic and highly effective foreign coal-mining enterprises by $25 \%-$ $45 \%$, and by $10 \%-15 \%$ more due to the involvement in primary mining ensuring high-performance functioning of the main mine technical equipment (Popov, Gribin \& Mohnachuk, 2013).

The technique is developed to assess the growth of labor productivity and identify intra-production reserves on the basis of decrease (increase) in settlement number of workers due to change of quantitative and qualitative factors which allow revealing, systematizing and realizing intra-production reserves of growth of labor productivity. On the basis of research and generalization of cross-sectoral industry experience authors suggest improved approach to the system factor analysis. This method provides not only quantitative, but also fuller assessment of quality indicators (organizational, economic, social), which allows to open the internal reserves. It should be noted that the set and structure of factors depend on specific objectives of the analysis, conditions of production and work in the coal-mining organizations.

\section{REFERENCES}

Kasakov, V. B., Popov, S. M., Stoyanova, I. A., \& Harchenko V. V. (2012). Methodological bases of an assessment of value of coal-mining waste for expansion of scales of their use in economic activity. Coal. 4: pp. 50-53.

Kostyukhin, Y. Y., \& Guseva, M. E. (2008). System of grades: possibilities of application in modern conditions. Economy in the industry. 1: pp. 53a-57.

Petrov, I. V. (2013). Scientific and educational centers as basis of staffing of development of mining industries. In the collection: Supply and demand in labor market and the market of educational services in regions of Russia in materials of the Tenth All-Russian scientific and practical Internet conference (on October 30-31, 2013). Book of I. Under V. A. Gurtov's ed. Petrozavodsk, pp. 185-194.

Petrov, I. V., Savon, D. Y., \& Stoyanova, I. A. (2014). Ecological and economic consequences of restructuring of the coal industry of East Donbass and way of their decision. Mountain information and analytical bulletin (scientific and technical magazine). 5: pp. 276-283.

Popov, V. N., Gribin, Y. G., \& Mohnachuk, I. I. (2013). Estimate of the complexity, severity and attractiveness of work - the basis of the scientific design of professional standards of workers in mining opencast. Coal. 10; pp. $46-49$.

Redina, M. M., \& Kalinin, A. R. (2011). The analysis of stability of ekologoeconomic systems of the enterprises on the basis of economic criteria. The Scientific bulletin of the Moscow state Mining University. 5: pp. 69-76.

Savon, D. Y. (2005). Social and economic policy in the regional market of employment. The Account and statistics. 5: pp. 29-33.

Savon, D. Y. (2013). Financial tools of investment of projects of publicprivate partnership in the region. The Mountain information and analytical bulletin (the scientific and technical magazine). S3 (1): pp. 315-319.

Savon, D. Y. (2014). Methodological approaches of financing of the sphere of environmental management in the conditions of a sustainable development of the region. The Mountain information and analytical bulletin (the scientific and technical magazine). 1: pp. 282-286.

Harchenko, V. A., Petrov, I. V., Kazakov, V. B., \& Zaytsev, S. P. (2012). Directions of improvement of system of staffing of the enterprises of a mining complex of economy of Russia. Scientific bulletin of the Moscow state Mining University. 3: pp. 134-139.

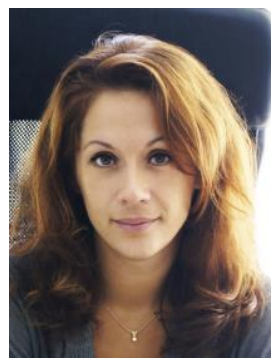

Kalacheva Larisa is a Candidate of Economic Science, the Doctoral Candidate of open JSC Tsnieiugol (The central research institute of economics and scientific and technical information). Address: Leninsky Avenue, 29 p. 6, 119071, Moscow.

E-mail: kalacheva@mail.ru

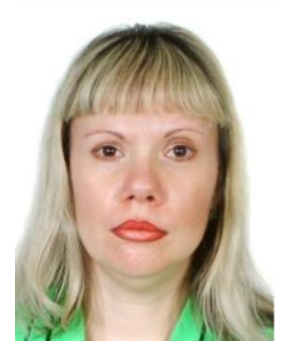

Savon Diana is Dr. oec., Professor, Chair of Economy of Mining of NUST "MISiS".

Address: Leninsky Avenue, p. 6, 119071, Moscow.

E-mail: di199@yandex.ru 